\title{
Fetal ultrasound of type 2 and 3 Chiari malformation
}

\author{
Ayşegül Altunkeser and Turgay Kara* \\ Department of Radiology, University of Health Science, Konya Trainning and Research Hospital, Konya, Turkey
}

\begin{abstract}
Ultrasound is a very valuable modality which gives us important information about evaluation of fetal anatomy, growth monitoring, early detection of congenital anomalies. By second trimester ultrasonography scan, approximately $70-90 \%$ of fetal congenital anomalies can be detected. Central nervous system anomalies, including Chiari malformations, are among the most important. Chiari malformed fetuses have high morbidity and mortality due to reasons such as postoperative care and tracheostomy, gastrostomy. Early identification of the disease is very important in terms of setting up a clinic with neurosurgery for follow-up pregnancy and cesarean section or termination of voluntary pregnancy within legal time. Today more than 3 types of Chiari malformations are defined. Chiari type II malformation is the most common type and accompanied by meningomyelocele. Type III malformation is a rare type of meningoencephalocele seen in the upper cervical region. In this case report, we presented two cases of Type 2 and Type 3 Chiari malformation with sonographic stimulant markers who were referred to our clinic for obstetric US.
\end{abstract}

\section{Introduction}

Although the cause of neural tube defects and Chiari malformation is not completely known, it is thought to be caused by a problem that leads to abnormal brain formation during fetal development. Chiari malformation may result in exposure to harmful substances during fetal development or may be associated with genetic problems and syndromes with familial transmission. Experience and careful examination are important in fetal diagnosis. Small open neural tube defects may be overlooked despite careful examination. Symmetrical flattening of the ventral part of the cranium called 'lemon sign' and cerebellar findings are associated with neural tube defect taking the name of banana sign and used as a sonographic indicator of spinal disraphism [1].

In this case report, we presented two cases of Type 2 and Type 3 Chiari malformation with sonographic stimulant markers who were referred to our clinic for obstetric US.

\section{Case 1}

39 years old (Gravida: 4 Parity: 2 Living: 2 Abortus: 1) pregnant woman applied our clinic for routine obstetric ultrasonography. According to the biometric measurements performed on the obstetric US, a single fetus was observed that was compatible with 17 weeks and 3 days. Fetal growth and amniotic index was in normal ranges. Bifrontal indentation (lemon sign) and banana sign in posterior fossa were noted in neurocranium imaging (Figures 1a and 1b). Dilatation $(12 \mathrm{~mm})$ was present in both lateral ventricles and cortical thinning was detected. Left deviation in the lumbosacral region and fusion defect compatible with spina bifida in the posterior elements of the vertebrae were detected (Figures $2 \mathrm{a}$ and $2 \mathrm{~b}$ ). The diameter of the renal AP was increased to $5.5 \mathrm{~mm}$. These findings suggested Chiari type 2 in the patient.

\section{Case 2}

A 23-year-old (Gravida: 3 Parity: 1 Living: 1 Abortus: 1) pregnant woman applied for obstetric ultrasonography. By biometric measurements at sonographic examination a single fetus that did not have growth retardation consistent with 18 weeks was detected. The amount of amnion was normal. Bifrontal indentation-lemon sign finding was observed on neurocranium imaging. The occipital bone had a defective appearance and a $24 \mathrm{~mm}$ diameter sac compatible with encephalocele was detected. The posterior fossa structures were all within the pouch (Figure 3). Spinal column was intact, there was no fusion defect. These findings suggest Chiari type 3 in the patient.

Both patients had no medical drug intake and maternal infection history during the pregnancy.

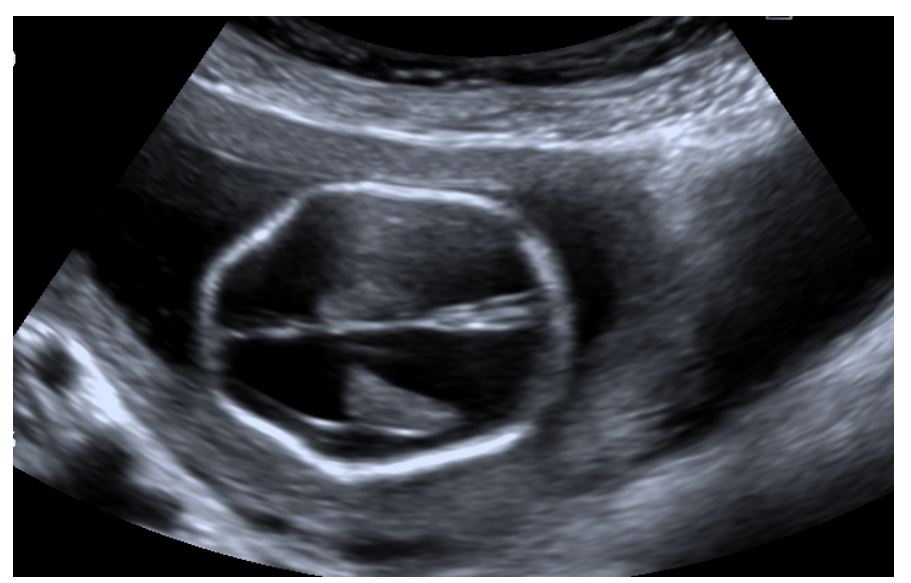

Figure 1a. Lemon sign

Correspondence to: Turgay Kara, MD, Konya Eğitim ve Araştırma Hastanesi, Radyoloji Bölümü, Hacı Şaban Mah, Meram Yeni Yol Caddesi, No: 97, PC: 42090, Meram, Konya, Türkiye, Tel: + 90 5055197559; Fax: 033232367 23; E-mail:trgykr@gmail.com

Key words: neural tube defect, spina bifida, lemon sign, banana sign, obstetric ultrasonography

Received: February 04, 2018; Accepted: February 19, 2018; Published: February 22,2018 


\section{Discussion}

Malformations associated with dorsal inductions such as Chiari malformation occur between 3rd-4th gestational weeks [2]. The Chiari malformation was first described by Chiari in 1891, following in 1894 by Arnold [3].

Currently 4 types are basically defined [4].

- Chiari I: $>5 \mathrm{~mm}$ descent of the caudal tip of cerebellar tonsils past the foramen magnum.

- Chiari II: brainstem, fourth ventricle, and $>5 \mathrm{~mm}$ descent of the caudal tip of cerebellar tonsils past the foramen magnum with spina bifida.

- Chiari III: herniation of the cerebellum with or without the brainstem through a posterior encephalocele.

- Chiari IV: Cerebellar hypoplasia or aplasia with normal posterior fossa and no hindbrain herniation.

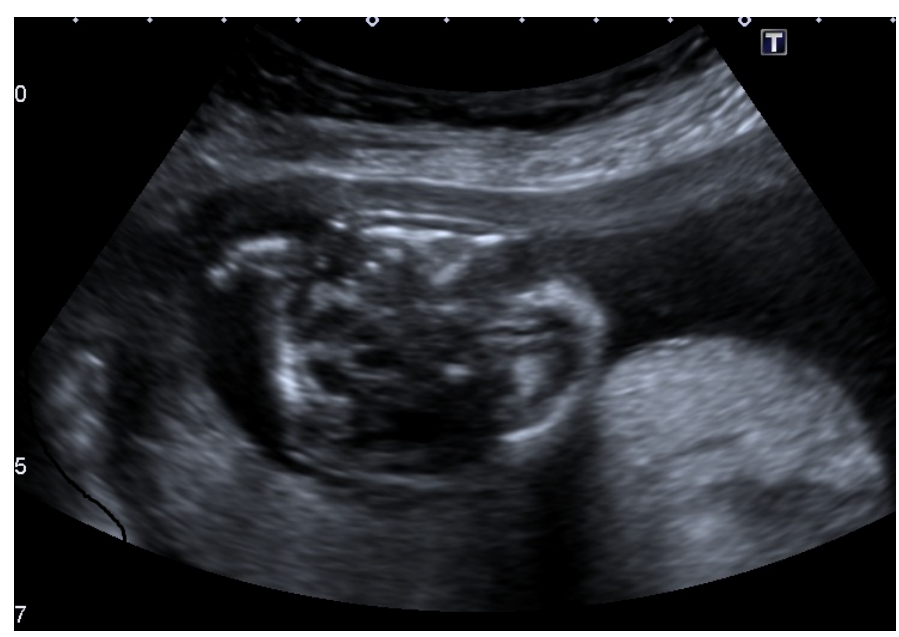

Figure 1b. Banana sign

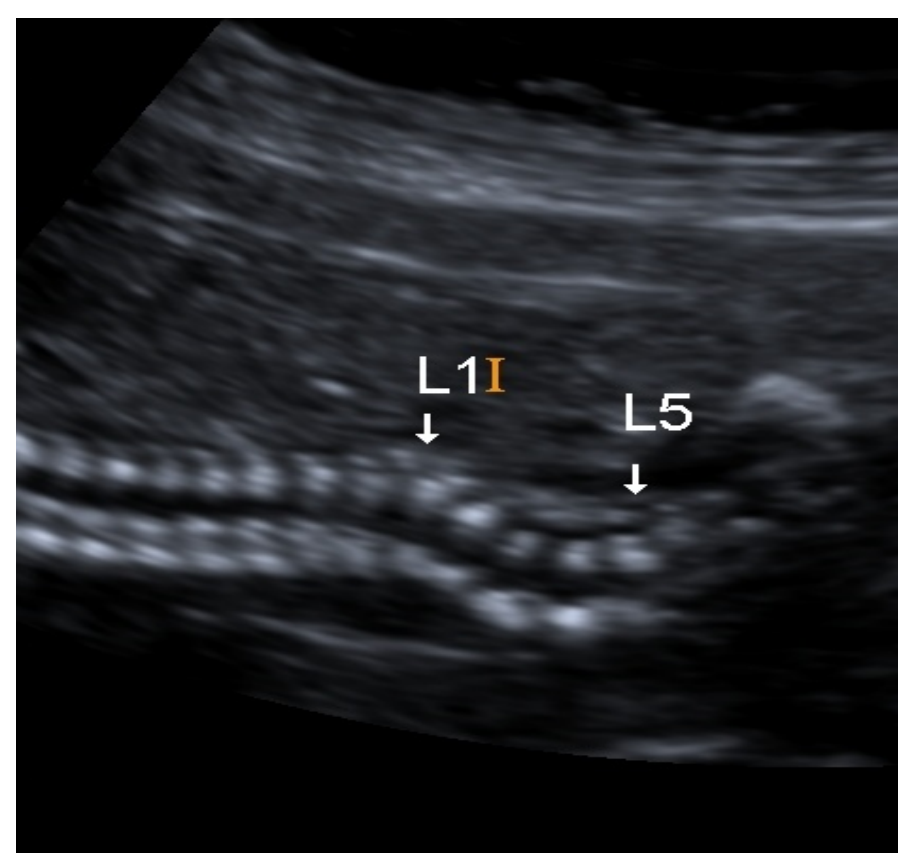

Figure 2a. Scoliosis

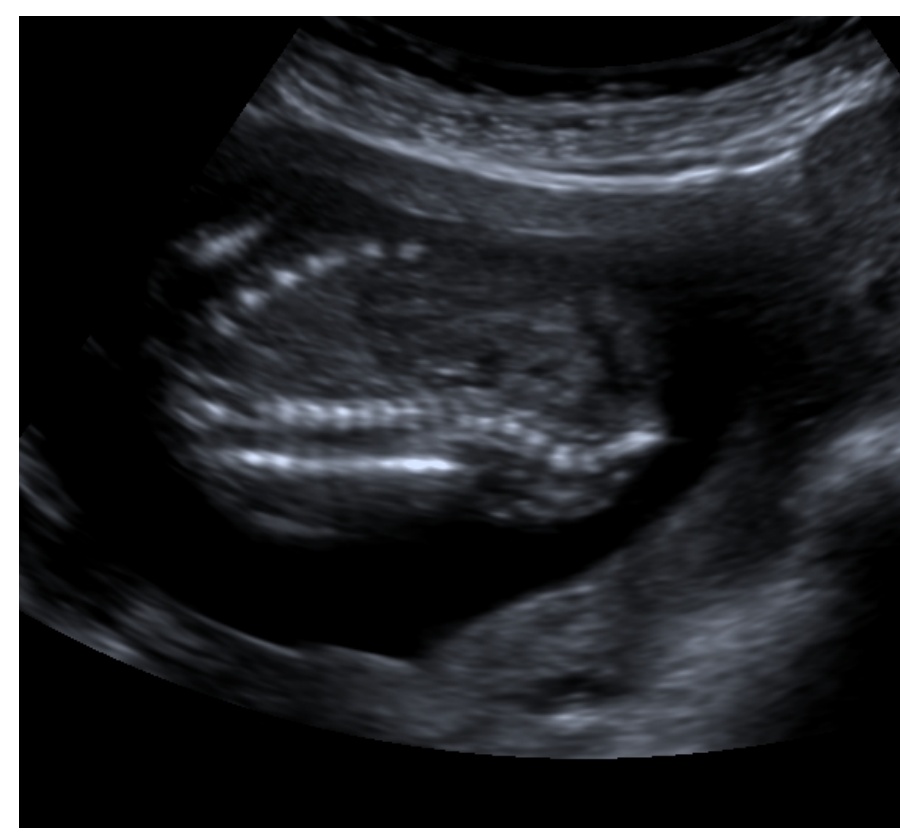

Figure 2b. Spina bifida

Chiari Type 1 is the most common form seen in adults and lasts asymptomatic till years, and the 4th ventricle is always in normal localization

It is suggested that the tonsils served as a natural protective sheath for neural structures around the foramen magnum against compression during the indentation of odontoid processes [5].

In Chiari type 2 malformation cerebellum, fourth ventricle and medulla oblongata displace from the foramen magnum into the cervical canal.

As a result, the cisterna magna is closed and the small, amorphous cerebellum is displaced towards the depths of the posterior fossa. Banana sign is used to describe this situation. It has been postulated that the decrease in the intraspinal pressure with spina bifida causes the brain to shift downward. This shift decreases the intracranial pressure, which is reflected onto the fetal cranium. The frontal bones are most vulnarable to decreased pressure and respond by flattening or scalloping inward [6]. Lemon sign is used to describe this situation. Lemon sign and / or banana sign are important sonographic markers of Chiari type 2 and spina bifida. The lemon sign is very helpful before 24-week gestation; but as the gestation age progresses, lemon marking may become obscured as a result of fetal development; so reliability is reduced $[7,8]$. Furthermore, it should be kept in mind that lemon sign is not specific to spina bifida and may be associated with encephalocele, Dandy-Walker malformation, cystic hygroma, diaphragm hernia, corpus callosum agenesis, fetal hydrops, umbilical venous varices and cord anomalies [9]. In the presence of lemon sign, cranial findings such as ventriculomegaly, microcephaly, cisterna magna obliterasyon, compression of cerebellar hemispheres and orientation in ventral direction should be examined and vertebral column carefully evaluated. In our sonographic examination, lemon sign was detected in both two cases, spina bifida was observed in Chiari 2 case while disraphism in the vertebral columnan or ventriculomegaly was not detected in Chiari 3 case. In Chiari 2 malformation, down herniation of the cerebellum and structures like brain stem may cause noncommunicative hydrocephalus by blocking the flow of cerebrospinal fluid. Increased cerebral pressure may cause nerve damage, dyspnea 


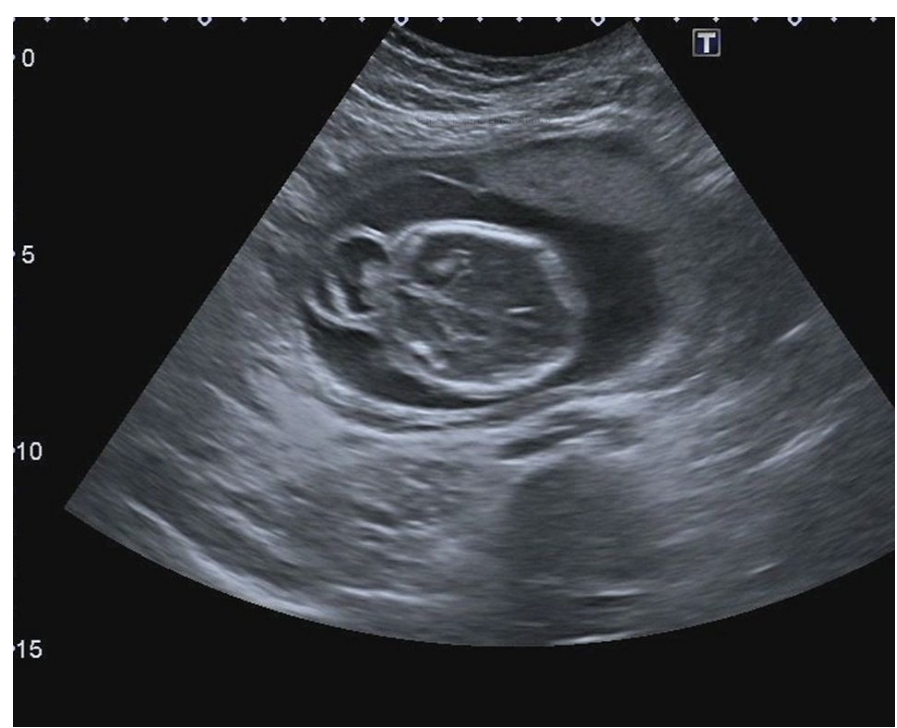

Figure 3. Encephalocele

and dysphagia by compressing the cerebellum, brain stem and cervical spinal cord [10]. In our Chiari 2 case, there was banana sign (Figure 3 ), ventriculomegaly, scoliosis and spina bifida in vertebral column in adition with lemon sign.

Chiari type 3 malformation is a rare anomaly associated with low occipital / high cervical encephalocele including small posterior fossa and posterior elements such as cerebellum, brainstem, occipital lobe or 4 th ventricle and early death is related to poor prognosis such as severe disability in the long term. Encephalocele including posterior fossa elements in the occipital region were observed in Chiari 3 case compatible with 19 weeks. Hydrocephalus may not have developed because Cerebrospinal fluid flow is not impaired from foramen Luschka and Magendie in our case. Since specific surgical procedures for Chiari type 3 have not been defined yet, approaches applicable to open neural tube defects may be applied to this disease [10].
The long-term effect of the disease varies according to the size of the defect, the presence and severity of hydrocephalus, and other accompanying malformations . Early diagnosis and treatment appears to be important. Inutero operated babies with Spina bifida apperta has decreased ventriculoperitoneal shunt requirement and better psychomotor development compared to postnatal operated babies [11].

Early diagnosis is crucial in setting up a clinic with neurosurgery for follow-up and cesarean section, or for terminating voluntary pregnancy within the legal time limit. Sonographic markers are guiding and ultrasonography is an important modality used in early diagnosis of chiari 2 and 3 malformations.

\section{References}

1. Robert D, Eduard K, Lydia F, Patrik S, Anna P, et al. (2010) Prenatal diagnosis of Arnold-Chiari syndrome using multi-slice view 3D/4D ultrasound and MRI. Actual Gyn 2: 17-20.

2. Juranek J, Salman MS (2010) Anomalous development of brain structure and function in spina bifida myelomeningocele. Dev Disabil Res Rev 16: 23-30. [Crossref]

3. Friede RL (1975) Developmental Neuropathology. Springer-Verlag Wien 253-266.

4. Hidalgo JA, Dulebohn SC (2017) Arnold Chiari Malformation StatPearls [Internet]. Treasure Island (FL): StatPearls Publishing.

5. Rahman A (2017) "Formation" of Chiari "malformation:" Nature's philosophical way of adaptation. J Craniovertebr Junction Spine 8: 291-3. [Crossref]

6. Nicolaides KH, Campbell S, Gabbe SG, Guidetti R (1986) Ultrasound screening for spina bifida: Cranial and cerebral sings. Lancet 2: 72-4. [Crossref]

7. Thomas M (2003) The lemon sign. Radiology 228: 206-7. [Crossref]

8. Sebire NJ, Noble PL, Thorpe JG, Snijders RJ, Nicolaides KH (1997) Presence of the lemon sign in fetuses with spina bifida at the 10-14-week scan. Ultrasound Obset Gynecol 10: 403-5. [Crossref]

9. Benacerraf BR, Stryker J, Frigoletto FD (1989) Abnormal US appearance of the cerebellum (banana sign): indirect sign of spina bifida. Radiology 171: 151-153. [Crossref]

10. Schoner K, Axt-Fliedner R, Bald R, Fritz B, Kohlhase J, et al. (2017) Fetal Pathology of Neural Tube Defects - An Overview of 68 Cases. Geburtshilfe Frauenheilkd 77: 495-50. [Crossref]

11. Graf K, Kohl T, Neubauer BA, Dey F, Faas D, et al. (2015) Percutaneous minimallyinvasive fetoscopic surgery for spina bifida aperta - Part III - Postnatalneurosurgical interventions in the first year of life. Ultrasound Obstet Gynecol 47: 158-1. [Crossref]

Copyright: (C2018 Altunkeser A. This is an open-access article distributed under the terms of the Creative Commons Attribution License, which permits unrestricted use, distribution, and reproduction in any medium, provided the original author and source are credited. 